\title{
Neonatal Hepatitis
}

National Cancer Institute

\section{Source}

National Cancer Institute. Neonatal Hepatitis. NCI Thesaurus. Code C84446.

Hepatitis developing during the neonatal period. 